\title{
Effectiveness of Online Education for the Professional Training of Journalists: Students' Distance Learning During the COVID-19 Pandemic
}

\author{
Irina A. Poluekhtova, Olga Yu. Vikhrova*, Elena L. Vartanova
}

Faculty of Journalism, Lomonosov Moscow State University, Moscow, Russia

* Corresponding author. E-mail: financialliteracymsu@gmail.com

Background. The necessity to introduce digital technologies in education and in the professional training of journalism students in particular has been widely discussed in the theory and practice of education over the past 20 years. From the point of view of both future research and training, it becomes very important to study the development of journalists' professional competencies and professional identity in the online environment.

Objective. To study the experience of distance learning by students in the faculty of journalism at Lomonosov Moscow State University during the period of restrictive measures in connection with the COVID-19 pandemic (Spring 2020).

Design. A two-stage empirical project studied the opinions of students about distance learning, to identify its effectiveness for the formation of professional competencies and identity. In the first stage, a qualitative (investigative) study was conducted on a small sample using semi-formalized tools. In the second stage, a formal survey was conducted on a representative sample $(\mathrm{N}=576)$.

Results. We found that in order to achieve the social, educational, and cognitive presence necessary for effective online education, an important condition is the communication environment and stable communication among all participants: students, professors, and academic departments. However, the communicative environment of the traditional training process is not transferred to the online environment in its original form. With Internet technologies, it is difficult to provide a strong teaching presence, which is a catalyst for the development of social and cognitive presence and a key component of traditional professional training. In the online learning mode, students are overloaded with self-study and written assignments, and mastering the necessary professional knowledge, competencies, and skills becomes their own responsibility.

Not all components of the traditional educational process (types and forms of classes, educational materials, etc.), remain effective when transferred to the online environment.

Conclusion. The formation of professional competencies, as well as the social, cognitive, and behavioral components that determine the further development of professional identity, is difficult in distance education. Online learning cannot be regarded as a full-fledged alternative to the traditional higher professional education of journalists.

Keywords:

professional identity, journalism students, online learning, teaching presence 


\section{Introduction}

For two decades, Russia has been undergoing an active digital transformation. Digital media has become the driver of the emergence of qualitatively new characteristics, previously not inherent in the modern structure of society. Widespread media communication technologies, development of social media platforms, and the emergence of a new generation of "digital youth" (Soldatova, Rasskazova, \& Nestik, 2017) have led to the dominance of digital media culture (Vartanova, 2019) and the formation of a digital educational environment (Blinova, 2020; Zvereva, 2019).

At present, digital technologies are crucial for the generation, transfer, and spread of scientific knowledge. This is not only because technology has changed science as such, but also because students, researchers, and professors apply them to their own academic practice, thereby transforming their fields of activity (Kramp, 2015). This is not just about the mediatization of communication and media research, but about changes in all disciplinary areas and niches of academic practice (Schäfer, 2014). This trend is confirmed by the fact that in the recent decades, online learning in the academic environment has been transformed from an experimental novelty into a full-fledged educational tool that is used almost everywhere. Already in 2011, over $75 \%$ of state colleges in the USA provided their students with a variety of online courses (Parker, Kim, \& Lenhart, 2013), and as of the 2018-2019 academic year, 14 Russian universities have established e-learning faculties and departments ${ }^{1}$.

But if before the COVID-19 pandemic, the active spread of online education allowed us to confidently assert only that every teacher and student would be involved in one or another of its forms at one of the stages of their training or career, then Q2 2020 showed that online learning is now an integral part of the educational process. In these conditions, the most important issue is how effective and relevant this form of training is for the training of specialists in each industry, in the development of both professional competencies and professional identity.

It is important to note that this article is not about well-planned online learning experiences, but about online learning during a crisis or disaster, which can only be considered as a temporary solution to an immediate problem and which researchers define as emergency remote teaching (Bozkurt et al., 2020; Hodges et al., 2020).

Training of students in the faculty of journalism at Lomonosov Moscow State University under the restrictive measures during the COVID-19 pandemic allowed us to collect sufficient empirical data for a primary analysis to determine whether it is possible to fully form the professional identity of journalists in the distance learning format, given the current development of digital technologies and on the basis of existing curricula.

It became necessary to introduce digital educational technologies and practices into the curricula of journalists about two decades ago. Already in the first decade of the 21 st century, training in modern information technologies became an important part of journalism curricula (Shiryaeva \& Svitich, 2007), and the universalization of journalistic processes in the context of media convergence required a search for fundamentally new approaches to training (Zassoursky, 2008). Among

1 RusBase, “14 universities where you can get online education”. https://rb.ru/list/vishka-udalenno/ (accessed on July 5, 2020). 
the personal psychological adaptive characteristics in the new working conditions, the following were highlighted:

- ability to use innovative work technologies (cloud technologies, databases, etc.);

- ability to quickly "adapt to the language of digital media" (to master new digital technologies, as well as multimedia ways to receive and transmit information for effective work with media content);

- ability to self-organize;

- ability to communicate with audiences via social networks;

- ability to work as a team and involvement in the results of teamwork (Svitich, 2013).

"Since young people see the future in Internet journalism, professors need to follow the trends and use information and communication technologies in the educational process," N. Avdonina (2017) emphasized.

However, although demand in the media industry has required some revision of curricula or their refocusing to new digital standards, the number of disciplines in curricula required to solve these issues is still a topic of discussion in the scientific community, and multimedia and digital journalistic programs are not at the top of the list in Russian higher education. At the same time, the changes made in the curricula of most universities are not fundamental, but mainly involve the addition of disciplines for acquiring software skills (Vartanova \& Lukina, 2014). A significant number of Russian journalism schools still focus on classical careers in print and broadcasting, and traditional competencies for journalists, reporters, and analysts are at the center of journalistic education. This is due to both the negative effects of regular long-term study online (Zinchenko et al., 2019), and the fact that the professional responsibilities of modern journalists still include traditional activities such as information gathering, news production, presentation and design of work, as well as editorial coordination and management. (Anikina, 2012). It has been empirically confirmed that regardless of the influence and extent of digital technologies, working with news and up-to-date information remains the essence of the journalistic profession. All this not only confirms the persistent relevance of the basic professional competencies and qualifications, but also reflects the traditional understanding and perception by journalists of their profession (Drok, 2014).

Despite this observed stability, the professional identity of journalists in its traditional meaning has been repeatedly called into question in the digital era. The decline in the importance of the gatekeeping function, the transition from monologue to regular and open dialogue with the audience, as well as the need to master new tools and media formats that form the modernized means of self-expression, have stimulated the research community to try to rethink journalistic roles and ideals (Eldridge \& Franklin, 2018; Koljonen, 2013; Nygren, Dobek-Ostrowska, \& Anikina, 2015).

Still, the professional identity of a journalist is permanent. "Regardless of the changes in technology or the economic situation, the journalist remains the journalist" (Craft \& Davis, 2016). We can speak about "multiple" identities in journal- 
ism only by classifying professional activity according to its specifics: TV journalist, business journalist, propagandist, etc. (Roccas \& Brewer, 2002). However, "journalism is still based on real fact and journalistic analysis" (Vartanova, 2010), and the basis of the profession remains its original and essential characteristics associated with the need to promptly provide the audience with important, hard, new, interesting and useful information" (Svitich, 2013). This is also confirmed by the fact that even when evaluating the views of digital journalists about their professional identity, Eldridge and Franklin (2018) distinguish only the move away from traditional hard news to analytical content and "proximity to the audience" postulated by digital journalists themselves, but in the context of media commercialization, the audience is the most significant agent of influence for any category of modern journalists (Anikina, 2012).

Modern journalism involves professional responsibilities, creativity, and social activity (Vartanova, 2009). That is why it is so important that when students enter university, they feel like journalists, and that the professors are perceived by them as colleagues and do not only perform the function of educators. "In any discipline, you can and should recreate the editorial model; in general, the educational process can be given an editorial atmosphere," Avdonina (2017) recommends. She also notes that it is possible to construct a successful educational process that contributes to the formation in students of a sense of affiliation with the profession only by taking into account three components of professional identity: emotional, cognitive, and behavioral.

Garrison, Anderson, and Archer (2001) identify three main components of successful online education: social, educational (teaching), and cognitive "presence". The first is defined as "the ability of community members to project themselves socially and emotionally as real people through the used communication environment" (Garrison, Anderson, \& Archer, 2000). The "teaching presence" is formulated by these researchers as "the development, promotion and direction of cognitive and social processes to achieve personally significant and educational learning outcomes" (Garrison \& Anderson, 2003), and "cognitive presence" is interpreted as "the degree to which the participants of any particular configuration of the research community can create meaning through stable communication". Higher-order education in an online learning environment can be achieved only by promoting cognitive presence (Garrison, Anderson, \& Archer, 2009).

Sun Anna and Chen Xiufang (2016) note that each presence plays a special role in development of the environment necessary for online learning. However, $\mathrm{Ke}$ (2010) emphasizes that it is the teaching presence that initiates the development of the student community and notes that cognitive presence in the online learning process can only occur if the teaching and social presence are well developed, and the development of social presence depends on how effectively the educational presence is implemented.

Evaluating the effectiveness of online learning, researchers also pay considerable attention to the role of the teacher in the organization and conduct of e-classes, including the development of online presentations, audio and video lectures, individual and group assignments, as well as recommendations for using the website on which the course is held (Garrison et al., 2009; Garrison \& Arbaugh, 2007; Kupczynski, Ice, \& Wiesenmayer, 2010). This aspect merits special attention, since 
online education contributes to the integration of future journalists into the digital environment, and the use of the relevant technologies in the educational process for students is not only preferable, but also necessary.

Our empirical research was conducted to find out how effectively the three above-mentioned presences are fostered in distance education from the point of view of journalism students themselves, as well as how social, cognitive, and behavioral components that determine the further development of professional identity are formed in the online environment for future media professionals.

\section{Methods}

\section{Procedure}

The empirical study compiled students' opinions, attitudes, and assessments about various aspects of distance learning. It was conducted according to the exploratory sequential mixed methods design, in a two-phase project, from May to June 2020.

First, an exploratory qualitative study of a small sample of students was conducted by using an e-mailed semi-structured questionnaire with a large number of open-ended questions, which was the only available survey tool during the lockdown. With this tool, qualitative data was collected in the form of field texts (narratives of respondents) that reflect the participants' experience and contain explanations, interpretations, and insights that are important for understanding research problems ${ }^{2}$. Analysis of these texts allowed us to delve into the topic, clarify research problems, identify variables to test, and develop formal tools for a subsequent quantitative survey.

The second phase included the collection of quantitative data of a representative sample of students in the faculty of journalism at Lomonosov Moscow State University, by a formalized Web-based questionnaire (Survey Monkey software was used for designing, gathering, and analyzing survey data).

The quantitative and qualitative data was integrated during data analysis to provide a better understanding of the research problem.

\section{Sample}

The sample comprised students in the faculty of journalism at Lomonosov Moscow State University. In the first phase, an available sample of the students in the third year of a bachelor's degree program was used to collect qualitative data; the sample included 68 students. The sample of the second stage was formed from the students of non-senior bachelor's (1, 2 and 3 years) and master's (1 year) degree programs. A total of 576 survey forms were received.

\section{Results}

The force majeure transfer to distance learning because of COVID-19 was accompanied by reorganization of the educational process and adaptation of traditional educational technologies to the online environment. Class hours were partially replaced by online classes with professors (via video conferences on various plat-

2 The quotes from the respondents' narratives are highlighted in italics. 
forms). This applied primarily to seminars and workshops, which were conducted according to the schedule on the Zoom online platform (less often, mostly at the beginning, via Skype), in the usual format of in-person seminars: questions and answers, discussion, reports, presentations by students.

The forms of online lecture classes were more diverse. In most cases, students received recorded lectures (audio/video files) or texts for self-study. These were sent to students by e-mail, sometimes posted on a special university website (learning portal) or YouTube. Online lectures (via video link with a professor) were less frequent - only a third of the respondents said that they had had such lectures.

In general, the transfer to distance learning has led to an increase in the study load and time spent. Almost all respondents (92\%) noted an increase in study load; two-thirds (67\%) felt this increase to be "significant", and 25\% "insignificant". Three-quarters of the respondents (74\%) indicated that they spent more time studying than they had before.

The increase in course load and time spent studying is primarily due to the increased amount of self-study. According to the students' assessment, only $20 \%$ of the total time spent studying was spent on scheduled online classes, and $80 \%$ on self-study, including written assignments, studying educational materials prepared by the professor (lectures, presentations, etc.), as well as required reading of fiction and recommended educational reading. Almost $40 \%$ of the study hours were spent on written assignments; this is the largest item of the "time" costs in the structure of the students' course load (Table 1):

\section{Table 1}

Distribution of study hours (in \%) by types of study load in online learning (according to students' assessments)

\begin{tabular}{lc}
\hline \multicolumn{1}{c}{ Type of study load } & \% \\
\hline Written assignments & 37 \\
Self-study of educational materials prepared by the professor & 21 \\
(lectures, presentations, etc.) & 20 \\
Scheduled online classes with professor & 14 \\
Required fiction reading & 8 \\
Recommended educational reading & \\
\hline
\end{tabular}

Although online classes with the professors took, on average, only $20 \%$ of the students' total study time, the vast majority of the respondents (94\%) attended all or the most of the classes. One in four (26\%) attended online classes more often than they had previously attended in-person classes. The high attendance at online classes could be explained by various reasons. First, attending online classes requires less additional effort and time (for preparation, travel, etc.). Second, with reduced personal contacts with professors and fellow students, the students began to appreciate this opportunity more and tried not to miss online classes with professors (the more so because the number of such classes decreased compared to the usual study mode, since many lecture courses were pre-recorded). 
The students' attitudes and ratings of the online learning experience are polarized: The number of those who generally liked this mode or whom it fit and the number of those who disliked or whom it didn't fit are equal (43\% and $43 \%$, Figure 1).

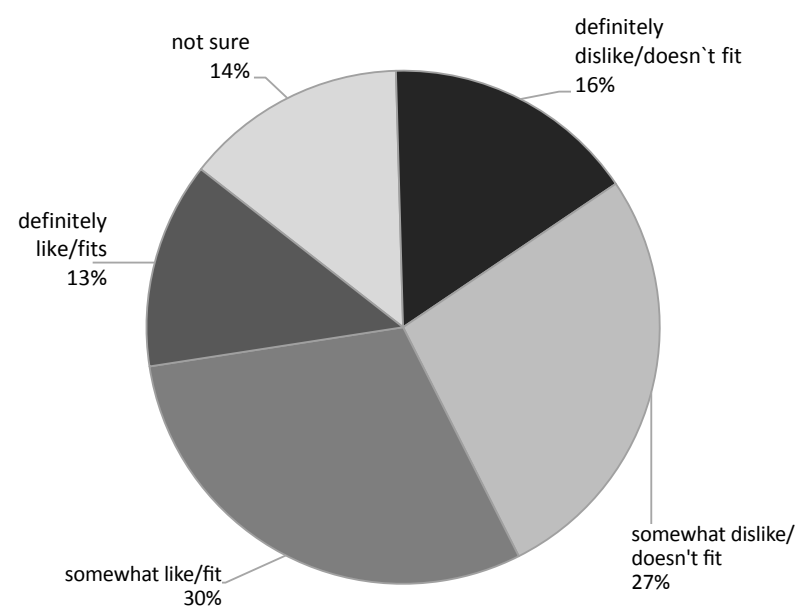

Figure 1. Assessment of distance education by students, \% of those surveyed

Some students were ambivalent about the effectiveness of distance learning: $40 \%$ of the respondents believe that the effectiveness has decreased during the distance mode, and $36 \%$ believe that it has not ( $24 \%$ were undecided).

This polarization of opinion reflects the contradictory nature of the online education process itself, which has both advantages and disadvantages (compared to traditional full-time education).

An obvious advantage of online learning, which received the maximum number of positive ratings from students, is greater freedom in managing their own time: saving time spent on the road, greater independence in planning the schedule of their learning sessions. An important bonus is the ability to study while also holding down a job, without losing quality. Overall, $92 \%$ of the respondents indicated these advantages.

The second significant advantage for many students is comfort and convenience: They could wake up later (even for the earliest class); there is no need to "get prepared"; they can eat lunch listening to the recorded lectures or listen while sitting in a comfortable chair, lying on a sofa, etc. Psychological comfort can also include the possibility to spend more time with family, which is significant for some respondents. The positive impact of the online learning format on the level of stress during classes, exams, and various types of tests was also noted. The comfort factor (home and psychological) was significant for $33 \%$ of the respondents.

But there are solid reasons for a negative attitude to distance education. First of all, this is a structural imbalance of the educational process, which is expressed in a significant increase in self-study and, above all, of written assignments and time spent on their completion. In our research, this received the highest number of negative ratings. Every second respondent (54\%) pointed to the large number 
of written assignments, and 38\% complained about the large amount of self-study materials.

This imbalance is an unavoidable result of the transfer of the learning process to the online environment. Many lecture courses (primarily streaming lectures), as already mentioned, were replaced by recorded video or audio lectures and were often accompanied by the distribution of additional educational materials for selfstudy. Verbal and other classroom forms of academic testing and performance rating (reports, presentations, discussions, etc.) were replaced by written assignments.

The increased amount of self-study and the unjustifiably large (in the opinion of the students) volume of written assignments ("for reporting") contributed to the increase in feelings of fatigue and stress:

"Education switches to self-learning in 90\% of cases. Moreover, the deadlines for many assignments are set on weekends, which makes it seem as if the studying goes on for days."

"The atmosphere of real education is lost. I feel like a bookworm who performs a huge number of tasks, and most of them are necessary neither for me nor the teacher, but 'for reporting' ".

"Training began to take ALL my time; strengths were lacking."

The second significant reason for dissatisfaction with online learning is related to the degradation of the usual communication environment and communication models between students and professors. One in three (35\%) respondents suffered from the lack of "live" communication with their fellow students. One in four (27\%) complained about the lack of direct, live communication with professors. Students also said they lacked feedback from professors on assignments and test papers (24\%). If the lack of communication with fellow students is more likely to be a psychological discomfort, the lack of direct contact and live communication with professors is directly related to the decreased effectiveness of the training process. "Unavailability", "impossibility to contact" some professors makes it difficult to master the educational material, according to the students:

"All the material has to be self-studied, without the possibility to clarify any details".

"Some material is difficult to learn independently; there is no live communication".

Students often interpreted the lack of the usual forms of communication in the online learning process as "low involvement" and "a negligent attitude" of professors, which offended them:

"We work hard, but only a few people respond and really assess us. It is frustrating, as if you are wasting time, although you really try to complete the assignments effectively. I also don't like the fact that it is not always clear whether the mails reach the professor, and there is often no confirmation".

In general, the research confirmed the high value of teaching presence for the students. This is also indirectly confirmed by the fact that students consider online seminars (via video link) with the professors the most effective form of classes during the distance learning mode (69\% of respondents). And the attendance at such seminars was higher than in the usual mode.

The effectiveness of the training process depends on many factors, including subjective and individual ones - personal circumstances, living conditions, psy- 
chological make-up of a student, etc. For example, some students (about 15\%) indicate that they experienced problems with self-organization, self-discipline, and time management in the distant mode, and difficulties studying at home, with other family members present. One in three admit that they feel uncomfortable and less confident in online classes than in regular classes and prefer to remain silent. Adaptation to distance learning caused difficulties for almost half of the respondents (46\%), and $17 \%$ were never able to fully adapt and experienced persistent difficulties and stress.

\section{Discussion}

The results of our research allow us to discuss the extent to which online education can effectively develop the professional competence of journalists and construct a successful training process that contributes to the formation of students' professional identity.

The two main problems in online learning identified in the study - the increased need for students' self-study and the lack of live communication with peers and professors - signal a weakening of the teaching presence in the online environment, which is the basis and catalyst for the development of social and cognitive presence. Transferring the learning process to the digital space of computer-mediated communication changes the interaction models of all participants. Not all students and professors are able to "project" themselves socially and emotionally in the online environment as well as they can in person. About a third of students feel less confident in online classes than in the classroom and prefer to remain silent. A weak social presence does not contribute to the formation of cognitive presence and, consequently, the cognitive component of professional culture.

The results of the study show that it was also problematic for professors to implement a successful social presence in the new communicative environment. Not all professors were able to successfully adapt academic tools to the conditions of the online environment, which led to a weakening of the educational presence, the basic component of a successful educational process. In an online communication environment, it is difficult to provide a strong educational (teaching) presence, as a result of which students are overloaded with self-study and written assignments, and mastering the necessary professional knowledge, competencies, and skills becomes their own responsibility.

Our research also showed that the educational and methodological support for the training of journalists is not transferred to the online environment without losses. Although professors were able to develop skills in creating online presentations, audio and video lectures, technical platforms for online classes, new formats for individual and group assignments, etc., not all courses in the journalism curriculum were adapted to the distance format, especially classes aimed at learning practical professional skills and competencies. In particular, case studies and the issue of educational media, according to the students, were ineffective and failed in the online mode.

At the same time, the forced experiment with online education led to new forms of training and teaching tools that passed "field testing". In particular, according to the students, recorded lectures were the most relevant form for online training, 
and the most successful formats of the recorded lectures were video lectures either "with a presentation" (55\%), or "with a teacher on camera" (52\%). The recorded audio lectures format received slightly fewer votes (32\%). Students would like to have access to a unified database of video lectures for each discipline to optimize the process of learning missed material, preparing for tests and exams. They positively assess the prospect of professors preparing a database of presentations in their disciplines, welcome digital forms for tests and online reporting (examinations and tests in Googledocs, Worddocs, etc.), which in the context of distance learning began to replace the archaic "paper" forms of tests and examinations. However, they do not consider digital learning materials as an adequate substitute for face-to-face classroom classes, but simply wish online materials (lecture records, notes, etc.) to systematically accompany (supplement) the face-to-face classes.

\section{Conclusion}

Based on the results of our empirical research, we can assess the components of the effectiveness of online education identified by Garrison, Anderson, and Archer (2001). We can talk about the weakness of the teaching presence, which is a catalyst for the development of social and cognitive presence and a key factor in the success of the educational process.

An important condition for the achievement of social, learning, and cognitive presence, necessary for effective online education, is a communication environment and sustainable communication among all participants - students, professors, academic departments. However, as our research shows, the communication environment of the traditional learning process is not directly transferred to the online mode. Many components of the traditional educational process and the formation of professional competencies of journalists lose their effectiveness when transferred to the online environment. In general, our research suggests that distance (online) education is not a full-fledged alternative to the traditional full-time education of journalists. However, it should be taken into account that our case is nontypical, since it is associated with an urgent transfer to distance learning format and the lack of appropriate training and time for adaptation of both educational technologies and teaching personnel and students. It seems that for more definite conclusions about the effectiveness of e-learning for professional training of journalists, more comprehensive research is necessary, comprising the digital media literacy of professors and students, testing the effectiveness of individual educational and methodological tools for the study of psychological readiness, and adaptation of professors and students to work in the online environment.

\section{References}

Avdonina, N.S. (2017). Izucheniye obraza professii zhurnalista $v$ vospriyatii studentov s tselyu korrektirovki obrazovatelnogo protsessa [Research on the image of the journalistic profession in the perception of students with the goal of adjusting the educational process]. Bulletin of Mari State University, 1, 96-106.

Avdonina, N.S. (2017). K probleme opredeleniya komponentov struktury professionalnoy identichnosti [On the problem of determining the components of professional identity]. Bulletin of Omsk State Pedagogical University, 4, 127-131. 
Blinov, V.I. (2020). Pedagogicheskaya kontseptsiya tsifrovogo professionalnogo obrazovaniya i obucheni$y a$ [The pedagogical concept of digital professional education and training]. Moscow: Russian Presidential Academy of the National Economy and Public Administration Federal Institute of Education Development Scientific Research Center for Vocational Education and Qualification Systems.

Bozkurt, A., \& Sharma, R.C. (2020). Emergency remote teaching in a time of global crisis due to CoronaVirus pandemic. Asian Journal of Distance Education, 15(1), i-iv. https://doi. org/10.5281/zenodo.3778083

Craft, S., \& Davis, C.N. (2016). Principles of American journalism: An introduction (2nd edition). Routledge. https://doi.org/10.4324/9781315693484

Drok, N. (2011). The shift of professional competences in journalism education. Retrieved from http:// www.mediascope.ru/node/859.

Eldridge, S., \& Franklin, B. (2018). The Routledge handbook of developments in digital journalism studies (1st edition). Routledge. https://doi.org/10.4324/9781315270449-1

Garrison, D. R., \& Anderson, T. (2003). E-learning in the 21st century: A framework for research and practice. London: Routledge/Falmer. https://doi.org/10.4324/9780203166093

Hodges, C., Moore, S., Lockee, B., Trust, T., \& Bond, A. (2020). The difference between emergency remote teaching and online learning. Educause Review, March 27, 2020. Retrieved from https:// er.educause.edu/articles/2020/3/the-difference-between-emergency-remote-teaching-and-online-learning

Garrison, D. R., Anderson, T., \& Archer, W. (2000). Critical inquiry in a text-based environment: Computer conferencing in higher education. The Internet and Higher Education, 2, 87-105. https://doi.org/10.1016/S1096-7516(00)00016-6

Garrison, D. R., Anderson, T., \& Archer, W. (2001). Critical thinking, cognitive presence, and computer conferencing in distance education. American Journal of Distance Education, 15, 7-23. https://doi.org/10.1080/08923640109527071

Garrison, D. R., Anderson, T., \& Archer, W. (2009). Critical thinking, cognitive presence, and computer conferencing in distance education, pp. 7-23. Published online: 24 Sep 2009.https://doi. org/10.1080/08923640109527071

Garrison, D. R., \& Arbaugh, J. B. (2007). Researching the community of inquiry framework: Review, issues, and future directions. The Internet and Higher Education, 10, 157-172. https://doi. org/10.1016/j.iheduc.2007.04.001

Ke, F. (2010). Examining online teaching, cognitive, and social presence for adult students Computers \& Education. https://doi.org/10.1016/j.compedu.2010.03.013

Koljonen, K. (2013). The shift from high to liquid ideals: Making sense of journalism and its change through a multidimensional model. Nordicom Review, 34, 141-154. https://doi.org/10.2478/nor2013-0110

Kramp, L. (2015). The digitization of science. Remarks on the alteration of academic practice. In L. Kramp, N. Carpentier, A. Hepp, I. Tomanić Trivundža, H. Nieminen, R. Kunelius, T. Olsson, E. Sundin, R. Kilborn (Eds.) Journalism, representation and the public sphere (pp. 239-251). Bremen: Edition lumière.

Kupczynski, L., Ice, P., Wiesenmayer, R., \& McCluskey, F. (2010). Student perceptions of the relationship between indicators of teaching presence and success in online courses. Journal of Interactive Online Learning, 9, 23-43.

Nygren, G., Anikina, M., Dobek-Ostrowska, B., \& Hök, J. (2012). Journalism in Russia, Poland and Sweden - Traditions, cultures and research. Journalistik, Södertörns högskola. Journalistik, Institutionen för kommunikation, medier och IT. Stockholm: E-Print. https://doi. org/10.1515/nor-2015-0018

Nygren, G., Anikina, M., \& Dobek-Ostrowska, B. (2015). Professional autonomy. Challenges and opportunities in Poland, Russia and Sweden. Nordicom Review, 36(2), 79-95. Sweden: Goteborg University.

Parker, K., Lenhart, A., \& Moore, K. (2013). The digital revolution and higher education: College presidents, public differ on value of online learning. Pew Internet \& American Life Project. 
Roccas, S., \& Brewer, M. B. (2002). Social identity complexity. Personality and Social Psychology Review, 6(2), 88-106. https://doi.org/10.1207/S15327957PSPR0602_01

Schäfer, M. S. (2014). The media in the labs, and the labs in the media: What we know about the mediatization of science. In K. Lundby (Ed.), Mediatization of Communication (pp. 571-591). Berlin, New York: Walter de Gruyter.

Soldatova, G.U., \& Rasskazova, E.I. (2017). Tsifrovaya situatsiya razvitiya mezhpokolencheskikh otnosheniy: razryv i vzaimodeystviye mezhdu podrostkami i roditelyami $v$ Internete [The digital situation of the development of intergenerational relations: Gap and interaction between adolescents and parents on the Internet]. Mir psikhologii [World of Psychology], 1, 134-143.

Soldatova, G.U., Rasskazova, E.I., \& Nestik, T.A. (2017). Tsifrovoye pokoleniye Rossii: kompetentnost $i$ bezopasnost [The digital generation of Russia: Competence and security]. Moscow: Smysl.

Sun, A., \& Chen, X. (2016). Online education and its effective practice: A research review. Journal of Information Technology Education: Research, 15, 157-190. https://doi.org/10.28945/3502.

Svitich, L.G., \& Shiryaeva, A.A., edited by Zassoursky, Ya.N. (2007). Innovatsionnyye podkhody $k$ proyektirovaniyu osnovnykh obrazovatelnykh programm po napravleniyu podgotovki vysshego professionalnogo obrazovaniya zhurnalistika [Innovative approaches to the design of basic educational programs for the higher professional degree in journalism]. Moscow: MSU.

Svitich, L.G. (2013). Model vypusknika - bakalavra zhurnalistiki [The model of the bachelor's degree graduate in journalism]. Bulletin of Chelyabinsk State University, 23. Series on Philology. Art History.

Vartanova, E.L. (2009). The current understanding of media and journalism. Media Almanac, 6, 6-15. Moscow: Non-profit partnership "Partnership of Journalism Faculties".

Vartanova, E.L. (2019). Professiya v kontekste industrii: o sovremennom ponimanii SMI i zhurnalistiki [Media education in the context of the development of society digital culture]. Media Almanac, 5(94), 8-10. Moscow: Non-profit partnership "Partnership of Journalism Faculties".

Vartanova, E.L., \& Lukina, M.M. (2014). New competences for future journalists: Russian journalism education executives evaluate industrial demand. World of Media. Journal of Russian Media and Journalism Studies. Moscow: National Association of Mass Media Researchers, 209-233.

Zinchenko, Y., Shaigerova, L., Dolgikh, A., Almazova, O., Shilko, R., \& Vakhantseva, O. (2019). Connection between the amount of time spent by Russian teenagers on the Internet and their psychological well-being. European Psychiatry, 56, S1. Netherlands: Elsevier BV. Retrieved from: https://www.morressier.com/article/07--connection-amount-time-spent-russian-teenagersinternet-psychological-wellbeing/5c642bef9ae8fb00131cfe7d.

Zassoursky, Ya.N. (2008). Zhurnalistskoye obrazovaniye: povestka na 2008 god [Journalism education: Agenda for 2008]. Bulletin of Moscow University. Series on journalism, No 1. 3-4.

Zvereva, L.G., \& Tkacheva, A.G. (2019). Etapy i puti stanovleniya tsifrovogo obrazovaniya v Rossii [Stages and paths of digital education in Russia]. Mezhdunarodnyy zhurnal gumanitarnykh $i$ estestvennykh nauk [International Journal of Humanities and Natural Sciences], 1-1. Retrieved from https://cyberleninka.ru/article/n/etapy-i-puti-stanovleniya-tsifrovogo-obrazovaniya-vrossii (accessed on: July 07, 2020).

Original manuscript received July 12, 2020

Revised manuscript accepted September 30, 2020

First published online December 01, 2020

To cite this article: Poluekhtova, I.A., Vikhrova, O.Yu., Vartanova, E.L. (2020). Effectiveness of Online Education for the Professional Training of Journalists: Students' Distance Learning During the COVID-19 Pandemic. Psychology in Russia: State of the Art, 13(4), 26-37. DOI: 10.11621/ pir.2020.0402 